Article

\title{
The Role of an Acidic Peptide in Controlling the Oxidation Process of Walnut Oil
}

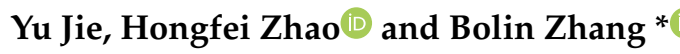 \\ Beijing Key Laboratory of Forest Food Processing and Safety, Beijing Forestry University, No. 35 Qinghua East \\ Road Haidian District, Beijing 100083, China; 13020021532@163.com (Y.J.); zhaohf518@163.com (H.Z.) \\ * Correspondence: zhangbolin888@163.com; Tel.: +86-10-62336154
}

Received: 20 August 2019; Accepted: 14 October 2019; Published: 15 October 2019

\begin{abstract}
Here, the mechanism of action of an antioxidant peptide rich in acidic amino acid residues in controlling lipid oxidation is discussed. Firstly, in the presence of this peptide, the fluorescence intensity of lipid peroxide in samples of walnut oil was very low, indicating that the peptide prevented the formation of lipid peroxides. Secondly, the production of lipid-derived radicals of oil was reduced by $23 \%$ following addition of the anti-oxidative peptide. Thirdly, Raman shifts of the lipid with the anti-oxidative peptide showed that acidic amino acid residues of the peptide were involved in delaying lipid oxidation. Finally, seven peptide inhibitors were synthesized with variations to the amino acid sequence of the original peptide, and Glu-Asp was proven to enhance the peptide's superoxide anion radical scavenging activity and decrease the formation of linoleic acid peroxides. Our findings emphasize the potential value of acidic amino acid residues in protecting unsaturated fatty acids from oxidation.
\end{abstract}

Keywords: lipid oxidation; antioxidant peptide; acidic amino acid residues

\section{Introduction}

Edible oils and fats are indispensable to the human diet. Unsaturated fatty acids (UFAs) exert many health benefits such as prevention of heart disease, hypertension, and diabetes [1-3]. Recently, there has been a rapid increase in the production of edible oils or fats enriched with selected UFAs [4]. However, these oils or fats often undergo autoxidation, eventually causing loss of flavor and nutritional value. Additionally, lipid peroxidation has negative effects on proteins, enzymes, and membrane structure, leading to damage to organs or tissues in the human body [5,6]. Thus, to protect UFA-enriched products, oxidation of these lipids must be decelerated.

Lipid oxidation is well-known to be a chain reaction induced by free radicals. In the initiation step, a lipid radical is formed by cleavage of a carbon bond or by transferring an initiator free radical to the hydrogen atom of a carbon bond. In the propagation step, molecular oxygen reacts with a lipid radical and then transfers a peroxyl radical to a hydrogen atom of the carbon bond to generate another carbon radical [7]. Therefore, once the oxygen-centered radicals or lipid-derived radicals are bound by a radical quencher, the chain reaction will slow down. Peptides are known to be free radical quenchers. Many extracted peptides show high resistance to linoleic acid oxidation, and the reason why these peptides can resist oxidation was attributed to their hydrophobic amino acid residues [8-11]. However, Saiga, Tanabe and Nishimura [12] proved that acidic amino acid residues in peptides were the key to reducing the oxidation of lipids. To date, no more studies have been done that explore the possibility of using peptides rich in acidic amino acid residues to retard lipid oxidation. Our previous work discovered the very promising antioxidant QITEGEDGGG, an acidic peptide that was effective in delaying the oxidation of walnut oil. It was found that after 30 days of storage, the peroxide value of the peptide-added walnut oil was only $1.2 \%$ higher than that of commercial antioxidant tertiary butyl 
hydroquinone (TBHQ)-added walnut oil, and 30\% lower than the peroxide value of antioxidant-free oil. We suspected that the acidic amino acid residues or glycine residues in the peptide acted to increase the antioxidant activity [13]. However, whether the presence of acidic amino acid residues enhances the antioxidant activity of the peptide remains incompletely understood.

In this study, we aimed to determine the mechanism by which the acidic peptide QITEGEDGGG inhibits the oxidation of lipids and test the effects of acidic amino acid residues of the peptide on inhibiting lipid oxidation. Specifically, the interaction between the peptide and lipid was evaluated, the lipid-radical formed during oxidation was monitored and characterized, and the ability of acidic amino acid residues of the peptide to inhibit lipid oxidation and scavenge oxygen radicals was investigated.

\section{Materials and Methods}

\subsection{Materials}

Seven peptides QITEGEDGGG， ITEGEDGGG，QITEGED， QEGEDGGG，QITEGGGG， HIQKEDVPSER, and HIQKVPSER were synthesized by SciLight Biotechnology Ltd. (Beijing, China) based on the literature $[13,14]$. Virgin walnut oil was provided by Xinmu Biotechnology Ltd. (Beijing, China). Linoleic acid, linolenic acid, arachidonic acid and oleic acid were purchased from J\&K Chemical (Hebei, China). Nt-butyl- $\alpha$-phenylnitrone (PBN) was obtained from Sigma-Aldrich (St. Louis, MO, USA). C11-BODIPY 581/591 was purchased from Thermo Fisher Scientific (Waltham, MA, USA) and fluorescein isothiocyanate (FITC) was purchased from Lablead Biotech (Beijing, China).

\subsection{The Mechanism of Action of Acidic Peptide in Oil}

\subsubsection{Preparation of Oil Samples}

According to EU regulations that limit the concentration of antioxidants in oil, $0.02 \mathrm{~g} / \mathrm{L}$ of the peptide QITEGEDGGG was added to walnut oil as the experimental sample. Walnut oil without any antioxidants was the control.

\subsubsection{Observation of Lipid Peroxide}

To clarify the action of the peptide QITEGEDGGG in inhibiting oxidation of walnut oil, the distribution of peptide and peroxides from oxidized oil droplets was observed. The inhibition of the formation of lipid peroxide by the peptide was monitored by confocal laser scanning microscopy (Leica SP8, Wetzlar, Germany). Both the experimental and control samples were stored at $37^{\circ} \mathrm{C}$ for 24 $\mathrm{h}$ for oxidation. The peroxides of the experimental sample and control were dyed by C11-BODIPY $581 / 591$, which is an ideal probe of lipid oxidation [3]. The peptide of the experimental sample was marked by FITC. The excitation wavelengths of C11-BODIPY 581/591 and FITC were at $568 \mathrm{~nm}$ and $495 \mathrm{~nm}$, respectively. Emission of C11-BODIPY 581/591 and FITC were monitored over the range of 570 to $640 \mathrm{~nm}$ (red channel) and 500 to $545 \mathrm{~nm}$ (green channel), respectively. The fluorescence intensity of peptide and peroxide was used to characterize the ability of the peptide to inhibit lipid oxidation.

\subsubsection{Evaluation of Lipid-Derived Radical Production}

The lipid-derived carbon-centered radicals of oxidized oil were studied to compare walnut oil oxidation taking place in the presence the peptide QITEGEDGGG with that taking place in the absence of the peptide. A JEOL FA-200 electron spin resonance (ESR) spectrometer (JEOL Ltd., Tokyo, Japan) was used to determine the intensity of lipid-derived radicals of the experimental and control samples during oxidation. PBN was used as an ESR spin trapper to capture the lipid-derived carbon-centered radicals in oxidized walnut oil [15]. First, $10 \mathrm{mg}$ PBN was dissolved in a $10 \mathrm{~mL}$ walnut oil sample to obtain a PBN-walnut oil mixture $(1 \mathrm{mg} / \mathrm{mL})$. Next, $0.02 \mathrm{~g} / \mathrm{L}$ of peptide was added to another PBN-walnut oil mixture. Two PBN-walnut oil mixtures were heated for oxidation. ESR spectra were 
measured every hour during the heating process until the appearance of the radical signal. Additionally, $10 \mathrm{mg}$ PBN was added to a peptide aqueous solution and treated under the same conditions. The ESR spectrometer settings were microwave power, $0.998 \mathrm{~mW}$; center field, $322.657 \mathrm{mT}$; sweep width, $5 \mathrm{mT}$; sweep time, $4 \mathrm{~min}$.

\subsubsection{Examination of the Lipid-Derived Radical}

Gas Chromatography and Mass Spectrometry (GC-MS) was employed to identify the type of lipid-derived radicals detected by the ESR spectrometer. The Shimadzu (Kyoto, Japan) GC-MS QP2010 ultra system was equipped with a Shimadzu AOC-20i auto injector and Rxi-5Sil MS fused silica capillary column $(30 \mathrm{~m} \times 0.25 \mathrm{~mm}$ I.D., film thickness $0.25 \mu \mathrm{m}, 5 \%$ phenyl $/ 95 \%$ dimethylpolysiloxane, Restek, Bellefonte, PA, USA). Helium was used as the carrier gas at a flow rate of $1.0 \mathrm{~mL} / \mathrm{min}$, and the injector port temperature was $250^{\circ} \mathrm{C}$ in split mode with a ratio of $1: 10$. The GC oven temperature was initially held at $35^{\circ} \mathrm{C}$ for $5 \mathrm{~min}$ and then increased to $320^{\circ} \mathrm{C}$ at a rate of $10^{\circ} \mathrm{C} / \mathrm{min}$ for $5 \mathrm{~min}$. The mass spectrometer was operated in the electron impact (EI) ionization mode at an ion source temperature of $200^{\circ} \mathrm{C}$. The GC-MS interface temperature was maintained at $250{ }^{\circ} \mathrm{C}$ and the electron energy was kept at $70 \mathrm{eV}$.

\subsubsection{Investigation of the Raman Shift of the Lipid}

To observe walnut oil changes before and after oxidation, the Raman shifts of the peptide QITEGEDGGG and UFAs in oil droplets were recorded (LabRAM HR Evolution, Horiba Jobin Yvon S.A.S., Longjumeau, France). Virgin walnut oil and walnut oil containing $0.02 \mathrm{~g} / \mathrm{L}$ of peptide QITEGEDGGG were heated to accelerate oxidation. Raman spectra were measured every hour during heating until the Raman signal showed. Additionally, a peptide dry powder was also treated with the same conditions to evaluate the Raman shift of the peptide. The parameters were as follows: excitation light source of $532 \mathrm{~nm}$ for average scan time of $15 \mathrm{~s}$, grating of 600 lines $\mathrm{mm}^{-1}$, and a sweep range of $200-2000 \mathrm{~cm}^{-1}$.

Linoleic acid, oleic acid, linolenic acid, and arachidonic acid are the four major UFAs in walnut oil $[16,17]$. Therefore, the Raman shifts of these four UFAs with or without the addition of the peptide were also examined as they underwent the process of oxidation. The spectra were acquired using the following conditions: the excitation light source of $785 \mathrm{~nm}$, exposure time $30 \mathrm{~s}$ for 20 exposures, grating of 600 lines $\mathrm{mm}^{-1}$, and a sweep range of $200-2000 \mathrm{~cm}^{-1}$.

\subsection{Effect of Acidic Amino Acid Residues in Anti-Oxidative Peptides}

\subsubsection{Superoxide Radical Scavenging Assay}

To probe the acidic amino acid residues' activity in the anti-oxidative peptide QITEGEDGGG, the antioxidant activities of seven synthesized peptides (QITEGEDGGG, ITEGEDGGG, QITEGED, QEGEDGGG, QITEGGGG, HIQKEDVPSER, and HIQKVPSER) were measured by a superoxide radical scavenging assay. The following reaction system was used. First, the seven synthesized peptides were dissolved in deionized water. Then, $0.30 \mathrm{~mL}$ of each peptide solution was mixed with $0.75 \mathrm{~mL}$ of dihydronicotinamide adenine dinucleotide $(936 \mu \mathrm{M}), 0.75 \mathrm{~mL}$ of nitro blue tetrazolium $(300 \mu \mathrm{M})$, and $0.75 \mathrm{~mL}$ of phenazine methosulfate $(120 \mu \mathrm{M})$ [13]. The solutions were incubated for $5 \mathrm{~min}$ and then the absorbance was read at $560 \mathrm{~nm}$. The superoxide anion-scavenging activities of peptide inhibitors were calculated as follows:

$$
\text { Superoxide anion scavenging-ability }(\%)=(1-(\text { Asample/Acontrol })) \times 100 \%
$$

where Acontrol was the absorbance without sample and Asample was the absorbance with sample. 


\subsubsection{Linoleic Acid Peroxidation Inhibition Assay}

The ability of the seven synthesized peptides (QITEGEDGGG, ITEGEDGGG, QITEGED, QEGEDGGG, QITEGGGG, HIQKEDVPSER, and HIQKVPSER) to inhibit the oxidation of linoleic acid was evaluated as described by Jie et al. [13]. Linoleic acid and Tween $20(1: 1 v / v)$ were mixed in phosphate buffer $(0.2 \mathrm{M}, \mathrm{pH} 7.0)$ to obtain a linoleic acid emulsion. Each peptide solution was combined with an equivalent volume of linoleic acid emulsion and incubated in the dark at $37^{\circ} \mathrm{C}$ for $24 \mathrm{~h}$, enabling oxidation. The degree of linoleic acid oxidation was determined from the ferric thiocyanate reaction. To assay $100 \mu \mathrm{L}$ of oxidative mixture, $4.7 \mathrm{~mL}$ of ethanol (75\%), $100 \mu \mathrm{L}$ of ammonium thiocyanate $(3.94 \mathrm{M})$, and $100 \mu \mathrm{L}$ of ferrous chloride $(0.02 \mathrm{M})$ solution in $\mathrm{HCl}(0.10 \mathrm{M})$ were added. The absorbance of the solution was read at $500 \mathrm{~nm}$ after $3 \mathrm{~min}$ of the reaction. The lipid peroxidation inhibition activity was calculated using the following equation:

$$
\text { Lipid peroxidation inhibition-ability }(\%)=(1-(\text { Asample/Acontrol })) \times 100 \%
$$

where Acontrol was the absorbance without sample and Asample was the absorbance with sample.

\subsection{Statistical Analysis}

The superoxide radical scavenging assays and linoleic acid oxidation inhibition assays were carried out in triplicate and the values represented as the mean \pm standard deviation (SD). Analysis of variance (ANOVA) with Tukey comparison was performed to measure the significance of differences and $(p<0.05)$.

\section{Results}

\subsection{The Mechanism of Action of an Acidic Peptide in Oil}

\subsubsection{Reduction of Lipid Peroxide}

The effects of the peptide QITEGEDGGG on lipid oxidation were examined by confocal laser scanning microscopy. The fluorescence signal of peroxide in oil droplets of walnut oil which underwent oxidation is displayed in Figure 1a. Figure $1 \mathrm{~b}$ is the fluorescence signal of peroxide in oil with the peptide added (peptide-oil) and Figure 1c presents the fluorescence signal of the peptide in the peptide-oil mix. Figure 1d represents the summary of the results from Figure 1a, Figure 1b,c. It is a comparison of peroxide level in peptide-free oil and peptide-oil mix, as well as the peptide level and peroxide level in peptide-oil mix. Peroxide level and peptide level are expressed as the mean value of intensity of fluorescence signals (A.U.). The mean value of the fluorescence intensity of peroxide in peptide-free oil was 988 A.U., while the mean value of the fluorescence intensity of peroxide in peptide-oil mix was 47 A.U. It can be seen that the production of peroxide in peptide-oil mix was reduced a lot. Furthermore, the fluorescence intensity of the peptide in the same oil droplet was also higher than that of the peroxide. Thus, data from Figure $1 \mathrm{~d}$ shows that the intensity of the fluorescence signal from the peroxide was reduced after the peptide was added to the walnut oil.

\subsubsection{Inhibition of Lipid-Derived Radical Production}

To investigate the lipid-derived radical or carbon-based radical scavenging activity of the peptide against lipid peroxidation, the radicals were trapped using PBN and detected by ESR. The ESR spectra of both oxidized walnut oil (OWO) and oxidized peptide-oil (OPO) were two typical triplet spectra (Figure 2a). The triplet spectra revealed a carbon-based radical trapped by PBN, which appeared as a composite signal. Figure $2 \mathrm{~b}$ shows that no radical is trapped in the heat-treated peptide solution or in un-oxidized walnut oil. Therefore, the peptide produced no carbon-centered radicals during lipid oxidation, and thus the lipid-derived radicals were all produced by walnut oil. The intensity of carbon-centered radicals was reduced by $23 \%$ in OPO compared with that in OWO. 


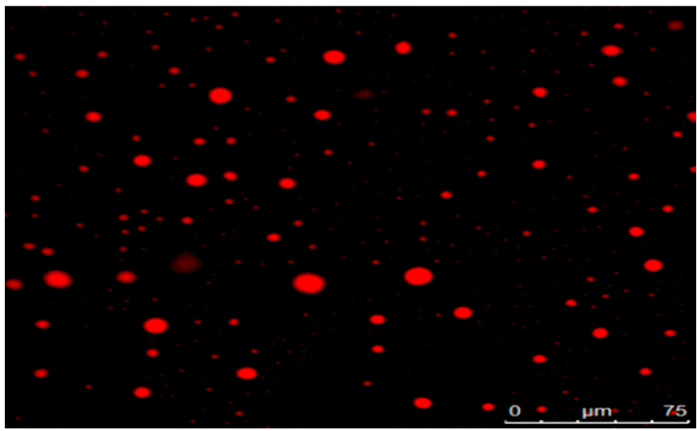

(a)

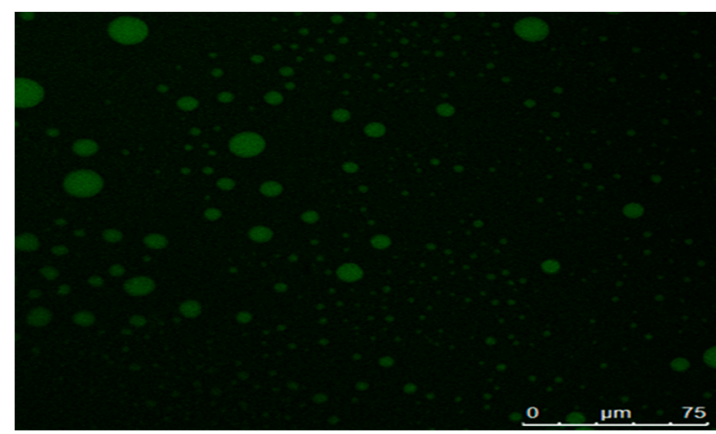

(c)

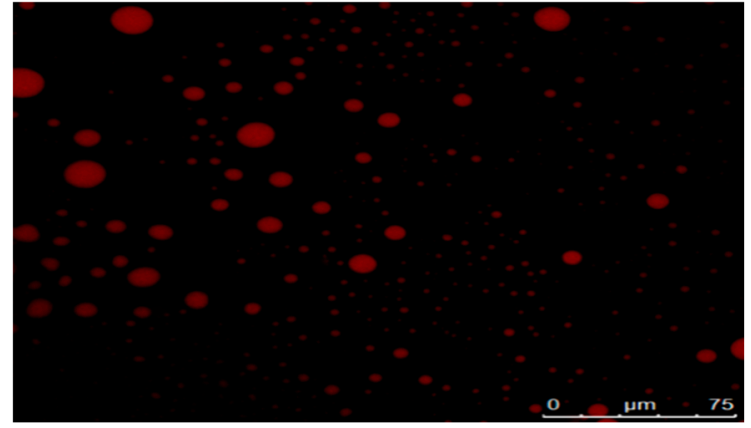

(b)

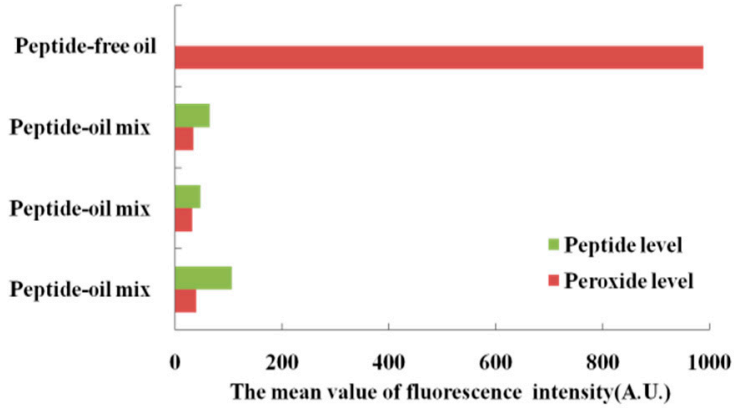

(d)

Figure 1. Effect of the peptide QITEGEDGGG against peroxides in oxidation oil. (a) The distribution of peroxide in walnut oil without any antioxidant. (b) The distribution of peroxide in peptide-oil. (c)The distribution of peptide in peptide-oil. (d) A comparison of the peroxide level in peptide-free oil and peptide-oil mix, as well as the peroxide level and peptide level in peptide-oil mix. Peroxide level and peptide level are expressed as the mean value of intensity of fluorescence signals (A.U.). Red fluorescence presents the signal intensity of C11-BODIPY, the dye associated with peroxides, while the green fluorescence is the signal intensity of FITC, the dye associated with the peptide. Scale bar is $75 \mu \mathrm{m}$.

GC-MS was used to identify the radicals. The results are the same as those obtained by ESR. Only one PBN adduct was detected by GC-MS ( $t_{R}=20.06 \mathrm{~min}$ ) (Figure $\left.2 \mathrm{c}\right)$. In addition, the substance $\left(t_{R}=10.16\right.$ and $10.95 \mathrm{~min}$ ) may be a degradation product of PBN. It was formed by the cleavage of the tert-butyl group from the PBN moiety and tentatively identified as benzaldehyde.

\subsubsection{Peptide Binding with UFAs}

The peptide scavenged lipid-radicals in $\mathrm{OWO}$, indicating that the peptide may react with walnut oil. Thus, the interaction between the peptide and walnut oil was examined by Raman microscopy. The Raman spectra of the un-oxidized oil, OWO and OPO in the range of $800-2000 \mathrm{~cm}^{-1}$ are shown in Figure 3a. The major peaks were observed at Raman bands of $1746 \mathrm{~cm}^{-1}$ (C=O stretching), $1658 \mathrm{~cm}^{-1}$ (cis-C $=\mathrm{C}$ stretching), $1439 \mathrm{~cm}^{-1}$ (C-H deformation), $1301 \mathrm{~cm}^{-1}\left(\mathrm{C}-\mathrm{H}\right.$ bending), $1264 \mathrm{~cm}^{-1}(=\mathrm{C}-\mathrm{H}$ bending), $1080 \mathrm{~cm}^{-1}$ (C-C stretching), $974 \mathrm{~cm}^{-1}$ (trans- $\mathrm{C}=\mathrm{C}$ bending), and $872 \mathrm{~cm}^{-1}(\mathrm{C}-\mathrm{C}$ stretching). No other peaks were generated in OPO and the intensity of the OPO remained unchanged, showing the same main peaks as un-oxidized oil. In contrast, the intensity of OWO was increased in all spectra.

The peptide played a role in preventing lipid oxidation, and its molecular conformation was unchanged after heating (Figure 3b). However, the Raman bands of the heat-treated peptide were enhanced at all shifts, particularly at $867 \mathrm{~cm}^{-1}$ (C-O-C stretching, O-O stretching), $1032 \mathrm{~cm}^{-1}$ (C-C stretching), $1249 \mathrm{~cm}^{-1}$ (amide III, C-N stretching, and N-H stretching), $1255 \mathrm{~cm}^{-1}$ (amide III, C-N stretching, and $\mathrm{N}-\mathrm{H}$ stretching), $1424 \mathrm{~cm}^{-1}\left(\mathrm{CH}_{2}\right.$ deformation and $\mathrm{CH}_{3}$ deformation), $1675 \mathrm{~cm}^{-1}$ 
(amide I, $\mathrm{C}=\mathrm{O}$ stretching, $\mathrm{N}-\mathrm{H}$ bending, and $\mathrm{C}-\mathrm{N}$ stretching). Comparison of Figure $3 \mathrm{a}, \mathrm{b}$ shows that the spectra of both peptide and walnut oil increased in intensity during oxidation, such as the bands at approximately $800-1000,1200,1400$, and $1600 \mathrm{~cm}^{-1}$. These shifts were associated with $C-C$ stretching, $\mathrm{C}-\mathrm{H}$ deformation, $\mathrm{C}-\mathrm{N}$ stretching, and $\mathrm{C}-\mathrm{O}$ stretching.

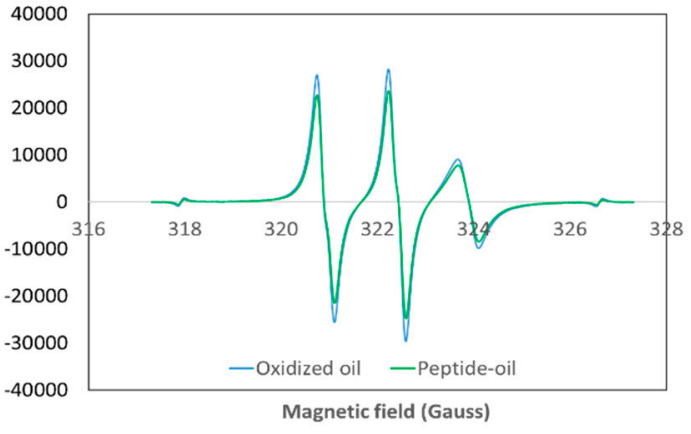

(a)

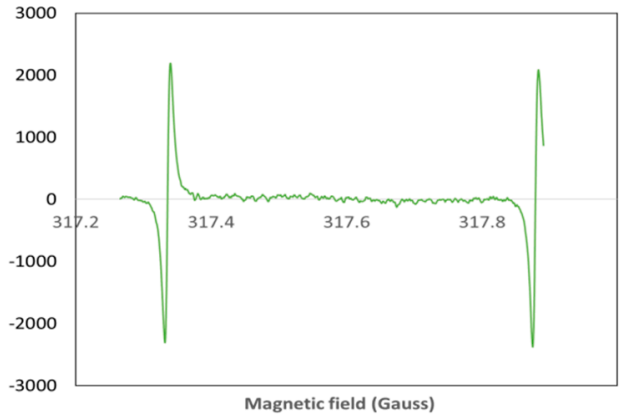

(b)

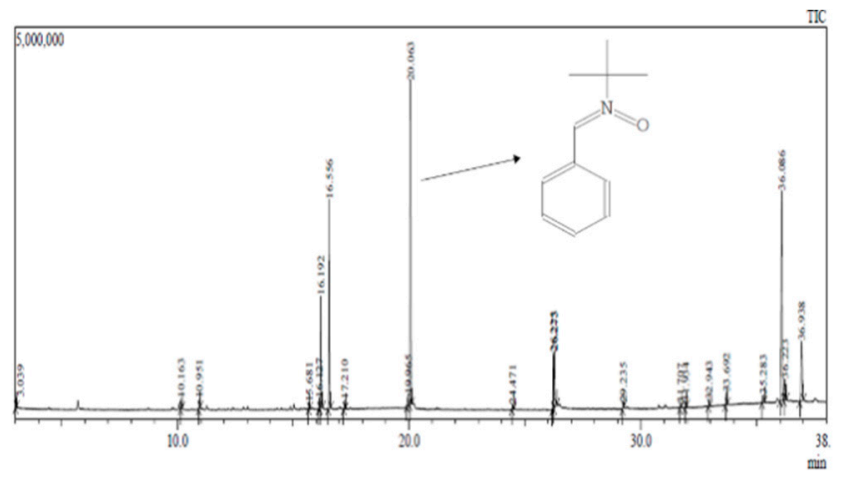

(c)

Figure 2. Effect of the peptide QITEGEDGGG against lipid radicals in oxidation oil. (a) ESR spectra of the PBN-radical adduct of walnut oil and peptide-oil during oxidation. (b) ESR signal of the heat-treated peptide solution. (c) GC-MS of the PBN-radical adduct in oxidized oil.

The Raman spectra of four UFAs with or without the addition of the peptide are shown in Figure 3c-f. Generally, the position of the main characteristic peaks of the Raman spectra of the four UFAs were the same as those of walnut oil. The Raman band at $1654 \mathrm{~cm}^{-1}$ stands for $c i s-\mathrm{C}=\mathrm{C}$ stretching, the region of $1439-1454 \mathrm{~cm}^{-1}$ stands for $\mathrm{C}-\mathrm{H}$ deformation, the band $1301 \mathrm{~cm}^{-1}$ stands for $\mathrm{C}-\mathrm{H}$ bending, the band $1264 \mathrm{~cm}^{-1}$ stands for $=\mathrm{C}-\mathrm{H}$ bending, and the band $1080 \mathrm{~cm}^{-1}$ stands for $\mathrm{C}-\mathrm{C}$ stretching. The shifts of the main peaks of the four UFAs with the peptide were lower than the spectral shifts of the four UFAs without it.

\subsection{Effect of Acidic Amino Acid Residues in Peptides}

In a previous study, the peptide QITEGEDGGG inhibited the production of superoxide anion radicals and linoleic acid oxidation by $86.46 \%$ and $60.37 \%$, respectively (Inhibitor No. 0 in Table 1) [13].

In this study, to verify whether acidic amino acid residues contribute to the antioxidant capacity of the peptide QITEGEDGGG, the amino acid residues in the peptide were removed systematically. Firstly, the amino acid residues at the beginning and end of the decapeptide were replaced in inhibitor No. 1 (ITEGEDGGG) and inhibitor No. 2 (QITEGED), respectively. The inhibitory activities of these two peptides were not significantly different from that of inhibitor No. $0(p>0.05)$. Thus, the amino acid residues at the beginning or end of the peptide did not affect their activity. Next, inhibitor No. 3 
(QEGEDGGG) was synthesized. The loss of the Ile and Thr amino acid residues had no effect on the ability of the peptide to scavenge superoxide anion radicals, and to inhibit lipid peroxidation.

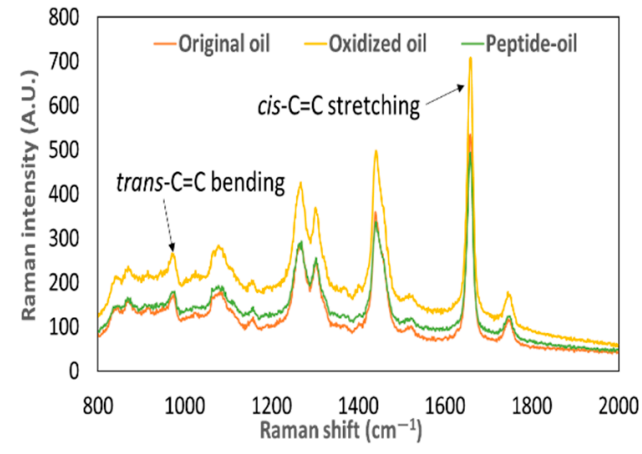

(a)

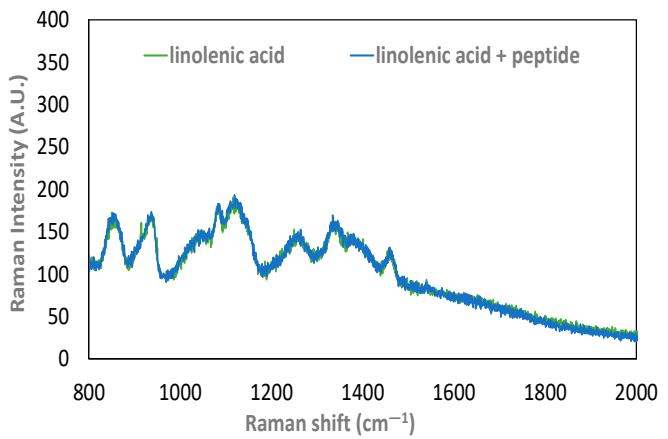

(c)

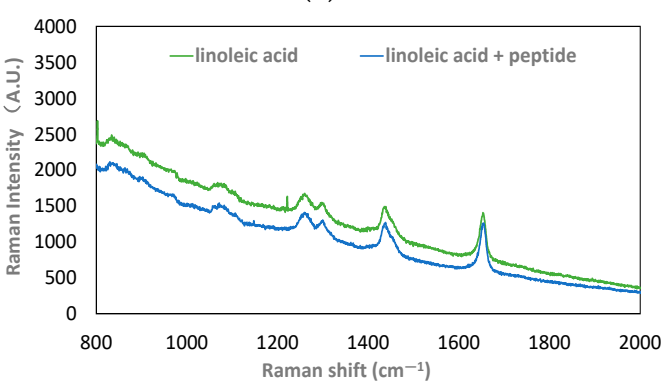

(e)

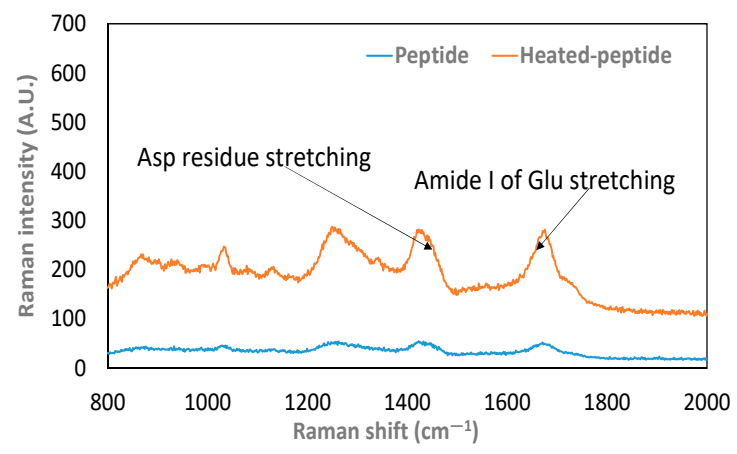

(b)

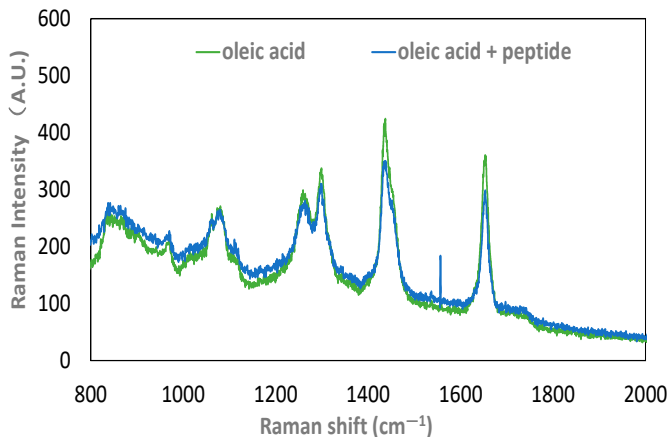

(d)

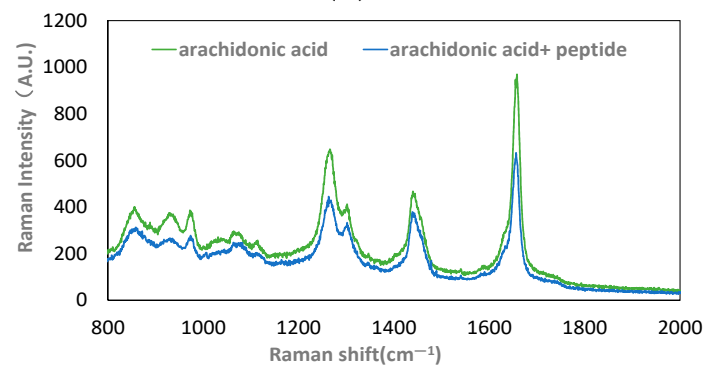

(f)

Figure 3. Raman spectra of lipid in the range from $800 \mathrm{~cm}^{-1}$ to $2000 \mathrm{~cm}^{-1}$. (a) Raman spectra of un-oxidized walnut oil, oxidized walnut oil, and oxidized peptide-oil. (b) Raman spectra of the peptide and the heat-treated peptide. (c) Raman spectra of oxidized linolenic acid and oxidized linolenic acid with peptide. (d) Raman spectra of oxidized oleic acid and oxidized oleic acid with peptide. (e) Raman spectra of oxidized linoleic acid and oxidized linoleic acid with peptide. (f) Raman spectra of oxidized arachidonic acid and oxidized arachidonic acid with peptide.

Lastly, Glu-Asp was removed from inhibitor No. 0 QITEGEDGGG and inhibitor No. 4 (QITEGGGG) was synthesized. Compared with inhibitor No. 0, the ability of inhibitor No. 4 to scavenge superoxide anion radicals and inhibit linoleic acid oxidation was significantly decreased $(p<0.05)$. Inhibitor No. 4 was only half as effective as inhibitor No. 0 in inhibiting oxidation of linoleic acids. Clearly, the presence of Glu-Asp affects the peptide's antioxidant activity. To check the efficacy of dipeptide Glu-Asp, the inhibitor No. 5 (ED) was synthesized. However, the antioxidant activity of dipeptide Glu-Asp was much lower than that present in the decapeptide. 
Table 1. The inhibitory activity of peptide inhibitors against superoxide anion radical and lipid oxidation.

\begin{tabular}{ccccc}
\hline Inhibitor No. & Sequence & $\begin{array}{c}\text { Inhibition of Superoxide } \\
\text { Anion Radical (\%) }\end{array}$ & $\begin{array}{c}\text { Inhibition of Linoleic } \\
\text { Acid Oxidation (\%) }\end{array}$ & Reference \\
\hline 0 & QITEGEDGGG & $86.46 \pm 0.07^{\mathrm{a}}$ & $60.37 \pm 0.16^{\mathrm{a}}$ & {$[13]$} \\
1 & ITEGEDGGG & $85.03 \pm 0.05^{\mathrm{a}}$ & $58.62 \pm 0.39^{\mathrm{a}}$ & \\
2 & QITEGED & $85.00 \pm 0.07^{\mathrm{a}}$ & $55.34 \pm 0.39^{\mathrm{a}}$ & \\
3 & QEGEDGGG & $85.54 \pm 0.23^{\mathrm{a}}$ & $53.49 \pm 0.35^{\mathrm{a}}$ & \\
4 & QITEGGGG & $64.14 \pm 0.02^{\mathrm{b}}$ & $31.11 \pm 0.17^{\mathrm{b}}$ & \\
5 & ED & $14.08 \pm 0.05^{\mathrm{c}}$ & $27.28 \pm 0.15^{\mathrm{c}}$ & \\
& & control & & \\
7 & HIQKEDVPSER & $87.28 \pm 0.01^{\mathrm{d}}$ & $52.53 \pm 0.13^{\mathrm{d}}$ & {$[14]$} \\
\hline
\end{tabular}

Values are given as the means $\pm \mathrm{SD}$ from triplicate determinations. a-e means in the same column with different letters differ significantly $(p<0.05)$.

By screening the amino acids in the decapeptide, it was determined that the acidic amino acids Glu-Asp are the active amino acid residues that confer the antioxidant activity of the peptide. To provide a comparison with the decapeptide and to begin to assess the generality of these observations, we drew upon the literature to synthesize a hydrophobic peptide containing Glu-Asp (HIQKEDVPSER inhibitor No. 6) and then synthesized a version of that peptide that eliminated the Glu-Asp amino acid residues (HIQKVPSER inhibitor No. 7) [14]. The superoxide anion radical scavenging activity of inhibitor No. 6 was significantly enhanced compared to that of inhibitor No. $7(p<0.05)$. The ability of inhibitor No. 7 to inhibit oxidation of linoleic acid was significantly decreased by $22 \%$ compared to that of inhibitor No. $6(p<0.05)$.

\section{Discussion}

Previous studies suggested that anti-oxidative peptides containing numerous hydrophobic amino acids or amino acids with $\mathrm{OH}$ groups could increase the oxidation resistance of linoleic acids [18-21]. The role of acidic amino acid residues has been mentioned, but few studies have been done to explore their significance.

In this work, we investigated the anti-oxidative properties of an acidic peptide and found that the acidic amino acid residues enhanced retardation of walnut oil oxidation. The walnut oil used in this test is comprised of 12,15 -octadecadienoic acid (55.13\%), 9-octadecenoic acid (20.32\%), hexadecanoic acid $(9.96 \%)$, stearate $(8.68 \%), 9,12$-octadecadienoic acid $(1.30 \%)$, and 11-eicosenoic acid $(1.21 \%)$. Other antioxidant components like tocopherol in walnut oil are present in minute quantities $(0.11 \%)$, and have negligible effect on controlling the oxidation process of walnut oil. Therefore, the added peptide QITEGEDGGG contributed to the retardation of oxidation of walnut oil.

Figures 1 and 2 demonstrated that the peptide QITEGEDGGG reduced the generation of lipid peroxides and the production of lipid-radicals. Although the ESR spectra did not exhibit hyperfine splitting into doublets, it can be concluded that the PBN radical adducts detected in our results were a mixture of carbon-based radicals by comparing our results with the literature using PBN or POBN as spin to trap lipid-radicals [15,22-28]. The PBN radical adducts are mixtures because of the viscosity of the oil, which results in decreased mobility of the radicals. The same phenomenon was also found by Thomsen, Kristensen and Skibsted [22] who observed triplets of doublet signals in rapeseed oil by ESR, but the doublets were not observed in all spectra.

Do acidic amino acid residues play a role in the above two aspects? Raman shifts of the un-oxidized walnut oil, OWO, OPO and the peptide proved that the acidic amino acid residues of peptide QITEGEDGGG were involved in retarding the lipid oxidation. The Raman bands at $1658 \mathrm{~cm}^{-1}$ and $974 \mathrm{~cm}^{-1}$ represented the cis-double bonds and trans-double bonds of PUFAs, respectively [29-31]. In case of $\mathrm{OWO}$, the expansion of the stretching vibration of cis-double bonds represented cis-fatty acid fragmentation. In contrast, the expansion of deformation of trans-double bonds indicated that the level of trans-fatty acids in walnut oil grew rapidly. $\mathrm{C}-\mathrm{C}$ stretching occurred in the region from 
872 to $1080 \mathrm{~cm}^{-1}$, indicating the fragmentation of fatty acids and thus generation of more carbon-based radicals to promote the chain reaction. The intensity increase of the band at $1746 \mathrm{~cm}^{-1}$ in the OWO represented a gradual break of $\mathrm{C}=\mathrm{O}$ in fatty acids, thus producing more fragmentation of the chain that enabled the peroxyl radical to be carried [7]. Contrarily, in the case of OPO, no increase in trans-fatty acids level and subsequent chain fragmentation was observed (Figure 3a). Likewise, the cis- $\mathrm{C}=\mathrm{C}$ stretching, $\mathrm{C}-\mathrm{H}$ deformation, $\mathrm{C}-\mathrm{H}$ bending, $=\mathrm{C}-\mathrm{H}$ bending, and $\mathrm{C}-\mathrm{C}$ stretching of the four UFAs in the presence of the peptide were slightly reduced (Figure $3 \mathrm{c}-\mathrm{f}$ ). We conclude that the peptide retards the fracturing of the $\mathrm{C}-\mathrm{H}$ bonds of UFAs.

It was noted that an increased intensity in the Raman shift of the peptide took place during oil oxidation (Figure 3b). The region between 1249 and $1255 \mathrm{~cm}^{-1}$ in the peptide spectra corresponded to the amide III band [32]. The increased intensity of the amide III band in the heat-treated peptide indicated alterations in the $\beta$-sheet of the peptide. The region of $800-950 \mathrm{~cm}^{-1}$ or $1500-1800 \mathrm{~cm}^{-1}$ represented the Raman spectra of acidic amino acid residues and their amides [33]. The band shift at $856 \mathrm{~cm}^{-1}$ was because of the $\mathrm{C}=\mathrm{O}$ stretching of the Gln residue. In addition, the band at $1670 \mathrm{~cm}^{-1}$ in the spectra of the peptide represents the amide I band stretching of Glu residues and the band at $1438 \mathrm{~cm}^{-1}$ is associated with the Asp residue. The stretching of acidic amino acid residues causes their side chains to be exposed, improving their radical scavenging ability and enhancing the anti-oxidative ability of the peptide. Apparently, the Glu and Asp residues of the peptide are involved in retarding the generation of cleaved C-H bonds of the UFAs. In addition, hydrogen bonding was formed between the peptide and the fatty acids from walnut oil because more overlap between the peptide and UFAs occurred in the Raman spectra. Our data showed that both $=\mathrm{C}-\mathrm{H}$ bending and $\mathrm{N}-\mathrm{H}$ stretching appeared in the same region (Figure 3). Stretching of the cis- $\mathrm{C}=\mathrm{C}$ of fatty acids and the shift in amide I of the Glu residue were observed in the same region.

Subsequently, we determined that the combination of Glu-Asp improved the antioxidant activity of peptides by screening the amino acids residues in the original decapeptide and synthesizing Glu-Asp-containing and Glu-Asp-missing peptide inhibitors (Table 1). In the absence of Glu-Asp, both superoxide anion radical scavenging activity and lipid anti-oxidative activity of peptide inhibitors were reduced. Acidic amino acid residues were reported to chelate metal ions to prevent lipid peroxidation [12,34]. However, in our previous studies (data not shown), the decapeptide, which was rich in acidic amino acid residues, failed to enhance the metal-chelating activity. In this study, the acidic amino acid combination Glu-Asp increased superoxide anion radical scavenging activity and decreased the generation of lipid peroxides. This suggests that acidic amino acid residues may limit the effects of metal ions by scavenging superoxide anions, and thereby obstructing the generation of $\mathrm{H}_{2} \mathrm{O}_{2}$, which promotes the oxidation of metal ions. Furthermore, the presence of acidic amino acid resides in peptides prevented the generation of lipid peroxides and the reaction of oxygen-centered radicals and lipid-derived radicals to form peroxyl radicals (Figure 4).

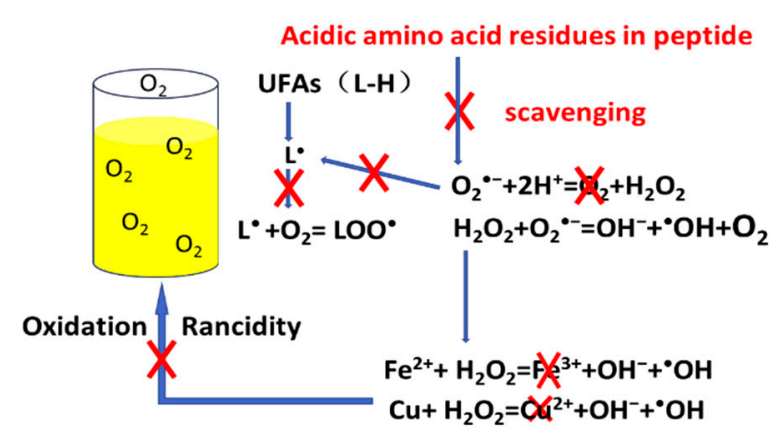

Figure 4. The possible mechanism of acidic amino acids in the peptide to resist oil oxidation. L-H

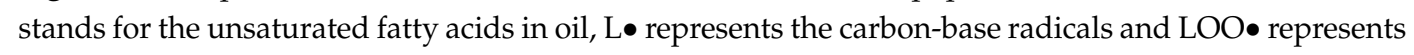
the peroxyl radicals. 
Based on our results, we speculate that a peptide would have high antioxidant activity if it has acidic amino acid residues.

\section{Conclusions}

The acidic peptide can reduce the oxidation of lipids, and this is most likely due to the acidic amino acid residues. Acidic amino acid residues were shown to eliminate oxygen-centered radicals and formed hydrogen bonds with UFAs. The combination of Glu-Asp in peptides has a positive effect on superoxide anion scavenging and inhibits oxidation of linoleic acid. Thus, we believe that acidic amino acid residues may reduce the lipid oxidation by their oxygen-centered radical scavenging activity and by decreasing formation of lipid peroxides. Our findings suggest that peptides containing Glu-Asp may guide development of further anti-oxidative peptides, which confer resistance to oxidation of UFA-enriched products.

Author Contributions: Y.J. and B.Z. conceived and design the experiment; Y.J. performed the experiment; Y.J. analyzed the data; H.Z. contributed reagents/materials/analysis tools; Y.J. wrote the paper; B.Z. revised the paper.

Funding: This research received no external funding

Acknowledgments: This work was financially supported by Xinmu biotechnology Ltd., a well-established corporation in China to produce organic foods.

Conflicts of Interest: The authors declare no conflict of interest.

\section{References}

1. Afonso, C.B.; Sousa, B.C.; Pitt, A.R.; Spickett, C.M. A mass spectrometry approach for the identification and localization of small aldehyde modifications of proteins. Arch. Biochem. Biophys. 2018, 646, 38-45. [CrossRef] [PubMed]

2. Kanavouras, A.; Coutelieris, F.A. Systematic transition from description to prediction for the oxidation in packaged olive oil. Food Chem. 2017, 229, 820-827. [CrossRef] [PubMed]

3. Banerjee, C.; Westberg, M.; Breitenbach, T.; Bregnhøj, M.; Ogilby, P.R. Monitoring Interfacial Lipid Oxidation in Oil-in-Water Emulsions Using Spatially Resolved Optical Techniques. Anal. Chem. 2017, 89, 6239-6247. [CrossRef] [PubMed]

4. Sainsbury, J.; Grypa, R.; Ellingworth, J.; Duodu, K.G.; Kock, H.L.D. The effects of antioxidants and shelf life conditions on oxidation markers in a sunflower oil salad dressing emulsion (SOSDE). Food Chem. 2016, 213, 230-237. [CrossRef]

5. Xu, L.; Yu, X.; Liu, L.; Zhang, R. A novel method for qualitative analysis of edible oil oxidation using an electronic nose. Food Chem. 2016, 202, 229-235. [CrossRef]

6. Qi, B.; Zhang, Q.; Sui, X.; Wang, Z.; Li, Y.; Jiang, L. Differential scanning calorimetry study-Assessing the influence of composition of vegetable oils on oxidation. Food Chem. 2016, 194, 601-607. [CrossRef]

7. Porter, N.A.; Caldwell, S.E.; Mills, K.A. Mechanisms of free radical oxidation of unsaturated lipids. Lipids 1995, 30, 277. [CrossRef]

8. Elias, R.J.; Kellerby, S.S.; Decker, E.A. Antioxidant activity of proteins and peptides. Crit. Rev. Food Sci. 2008, 48, 430. [CrossRef]

9. Guo, H.; Yoshiaki, K.; Masami, Y. Structures and properties of antioxidative peptides derived from royal jelly protein. Food Chem. 2009, 113, 238-245. [CrossRef]

10. Park, E.Y.; Murakami, H.; Mori, T.; Matsumura, Y. Effects of protein and peptide addition on lipid oxidation in powder model system. J. Agric. Food Chem. 2005, 53, 137-144. [CrossRef]

11. Beermann, C.; Euler, M.; Herzberg, J.; Stahl, B. Anti-oxidative capacity of enzymatically released peptides from soybean protein isolate. Eur. Food Res. Technol. 2009, 229, 637-644. [CrossRef]

12. Saiga, A.; Tanabe, S.; Nishimura, T. Antioxidant activity of peptides obtained from porcine myofibrillar proteins by protease treatment. J. Agric. Food Chem. 2003, 51, 3661-3667. [CrossRef] [PubMed] 
13. Jie, Y.; Zhao, H.F.; Sun, X.Q.; Lv, X.R.; Zhang, Z.; Zhang, B.L. Isolation of antioxidative peptide from Caragana ambigua seeds' protein hydrolysate and its mechanism in retarding lipid auto-oxidation. J. Sci. food Agric. 2019, 99, 3078-3085. [CrossRef] [PubMed]

14. Shanmugam, V.P.; Kapila, S.; Sonfack, T.K.; Kapila, R. Antioxidative peptide derived from enzymatic digestion of buffalo casein. Int. Dairy J. 2015, 42, 1-5. [CrossRef]

15. Qian, S.Y.; Yue, G.H.; Tomer, K.B.; Mason, R.P. Identification of all classes of spin-trapped carbon-centered radicals in soybean lipoxygenase-dependent lipid peroxidations of omega-6 polyunsaturated fatty acids via LC/ESR, LC/MS, and tandem MS. Free Radic. Biol. Med. 2003, 34, 1017-1028. [CrossRef]

16. Shamaei, S.; Seiiedlou, S.S.; Aghbashlo, M.; Tsotsas, E.; Kharaghani, A. Microencapsulation of walnut oil by spray drying: Effects of wall material and drying conditions on physicochemical properties of microcapsules. Innov. Food Sci. Emergy 2017, 39, 101-112. [CrossRef]

17. Li, B.; Wang, H.; Zhao, Q.; Ouyang, J.; Wu, Y. Rapid detection of authenticity and adulteration of walnut oil by FTIR and fluorescence spectroscopy: A comparative study. Food Chem. 2015, 181, 25-30. [CrossRef]

18. Li, B.; Chen, F.; Wang, X.; Ji, B.; Wu, Y. Isolation and identification of antioxidative peptides from porcine collagen hydrolysate by consecutive chromatography and electrospray ionization-mass spectrometry. Food Chem. 2007, 102, 1135-1143. [CrossRef]

19. Zhang, J.; Zhang, H.; Wang, L.; Guo, X.; Wang, X.; Yao, H. Isolation and identification of antioxidative peptides from rice endosperm protein enzymatic hydrolysate by consecutive chromatography and MALDI-TOF/TOF MS/MS. Food Chem. 2010, 119, 226-234. [CrossRef]

20. Tsopmo, A.; Romanowski, A.; Banda, L.; Lavoie, J.C.; Jenssen, H.; Friel, J.K. Novel anti-oxidative peptides from enzymatic digestion of human milk. Food Chem. 2011, 126, 1138-1143. [CrossRef]

21. Lin, Z.; Su, G.; Ren, J.; Gu, L.; You, L.; Zhao, M. Isolation and characterization of an oxygen radical absorbance activity peptide from defatted peanut meal hydrolysate and its antioxidant properties. J. Agric. Food Chem. 2012, 60, 5431-5437. [CrossRef]

22. Thomsen, M.K.; Kristensen, D.; Skibsted, L.H. Electron spin resonance spectroscopy for determination of the oxidative stability of food lipids. J. Am. Oil Chem. Soc. 2000, 77, 725-730. [CrossRef]

23. Williams, H.E.; Claybourn, M.; Green, A.R. Investigating the free radical trapping ability of NXY-059, S-PBN and PBN. Free Radic. Res. 2007, 41, 6. [CrossRef] [PubMed]

24. Janzen, E.G.; Towner, R.A.; Krygsman, P.H.; Haire, D.L.; Poyer, J.L. Structure identification of free radicals by EER and GC/MS of PBN spin adducts from the in vitro and in vivo rat liver metabolism of halothane. Free Radic. Res. 1990, 9, 9. [CrossRef]

25. Yue, Q.S.; Tomer, K.B.; Yue, G.H.; Guo, Q.; Kadiiska, M.B.; Mason, R.P. Characterization of the initial carbon-centered pentadienyl radical and subsequent radicals in lipid peroxidation: Identification via on-line high performance liquid chromatography/electron spin resonance and mass spectrometry. Free Radic. Biol. Med. 2002, 33, 998-1009. [CrossRef]

26. Polyakov, N.E.; Leshina, T.V.; Salakhutdinov, N.F.; Konovalova, T.A.; Kispert, L.D. Antioxidant and redox properties of supramolecular complexes of carotenoids with $\beta$-glycyrrhizic acid. Free Radic. Biol. Med. 2006, 40, 1804-1809. [CrossRef]

27. Chen, H.; Cao, P.; Li, B.; Sun, D.; Li, J.; Liu, Y. High sensitive and efficient detection of edible oils adulterated with used frying oil by electron spin resonance. Food Control. 2017, 73, 540-545. [CrossRef]

28. Buettner, G.R. Spin trapping: ESR parameters of spin adducts. Free Radic. Biol. Med. 1987, 3, $259-303$. [CrossRef]

29. Carmona, M.Á.; Lafont, F.; Jiménez-Sanchidrián, C.; Ruiz, J.R. Raman spectroscopy study of edible oils and determination of the oxidative stability at frying temperatures. Eur. Food Res. Technol. 2015, 116, 1451-1456. [CrossRef]

30. Chen, Q.; Xie, Y.; Xi, J.; Guo, Y.; Qian, H.; Cheng, Y.; Chen, Y.; Yao, W.R. Characterization of lipid oxidation process of beef during repeated freeze-thaw by electron spin resonance technology and Raman spectroscopy. Food Chem. 2018, 243, 58-64. [CrossRef]

31. Moudache, M.; Nerín, C.; Colon, M.; Zaidi, F. Antioxidant effect of an innovative active plastic film containing olive leaves extract on fresh pork meat and its evaluation by Raman spectroscopy. Food Chem. 2017, 229, 98-103. [CrossRef] [PubMed] 
32. Philippidis, A.; Papliaka, Z.E.; Anglos, D. Surface enhanced Raman and 2D-fluorescence spectroscopy for the investigation of amino acids and egg proteins. Microchem. J. 2016, 126, 230-236. [CrossRef]

33. Pazderka, T.; Kopecký, V. Drop coating deposition Raman spectroscopy of proteinogenic amino acids compared with their solution and crystalline state. Spectrochim. Acta Part A 2017, 185, 207-216. [CrossRef] [PubMed]

34. Suetsuna, K. Antioxidant peptides from the protease digest of prawn (Penaeusjaponicus) muscle. Mar. Biotechnol. 2000, 2, 5-10. [CrossRef] [PubMed]

(C) 2019 by the authors. Licensee MDPI, Basel, Switzerland. This article is an open access article distributed under the terms and conditions of the Creative Commons Attribution (CC BY) license (http://creativecommons.org/licenses/by/4.0/). 